\title{
Are stress and mixed urinary incontinence associated with impaired executive control in community-dwelling older women?
}

\author{
Maxime Lussier, Mélanie Renaud, Sima Chiva-Razavi, Louis Bherer \& Chantale Dumoulin \\ Published online: 08 May 2013
}

\begin{abstract}
Objectives: To assess whether stress or mixed urinary incontinence (UI) is associated with deficits in executive functioning among community-dwelling women. Design: An observational study comparing the performance, using multivariate analyses of variance (MANOVAs) and Bonferroni post hoc test, of continent women and women with stress or mixed UI during executive control tasks. Setting: The research center of the Institut universitaire de gériatrie de Montréal. Participants: One hundred and fifty-five community-dwelling women aged 60 and older participated in the study. Measurements: Based on the Urogenital Distress Inventory (UDI), participants were split into three groups: 35 continent women, 43 women with stress UI, and 78 women with mixed UI. Participants completed a battery of neuropsychological tests and a computerized dual-task test. Results: Women with mixed UI showed poorer performances than continent and stress UI women in executive control functions. Deficits were specific to tests involving switching and sharing/dividing attention between two tasks. Conclusion: Results of this study suggest that mixed UI can be associated with executive control deficits in community-dwelling older women. Future intervention studies in the treatment of UI should take the higher risk of an executive control deficit in women with UI under consideration.
\end{abstract}

Keywords: Cognition, Urinary incontinence, Executive control, Attention, Divided attention

Urinary incontinence (UI) is one of the most prevalent health concerns confronting women aged 60 and older (Milson et al., 2009; Tannenbaum, Mayo, \& Ducharme, 2005). In fact, up to 55\% of communitydwelling women (i.e., not institutionalized) suffer from UI. Of these, $20 \%$ to $25 \%$ suffer from severe symptoms (>10 episodes/week; Milson et al., 2009; Wetle et al., 1995). UI is subdivided into three types according to symptoms: (a) Stress UI refers to leakage on effort, exertion, sneezing, or coughing; (b) urgency UI refers to leakage accompanied by a sudden, intense desire to urinate; and (c) mixed UI refers to symptoms of both stress and urgency UI. Stress and mixed UI tend to predominate in women between the ages of 60 to 69 years, accounting for $43 \%$ of mixed UI, $40 \%$ of stress UI, and $12 \%$ of urgency UI in women (Abrams et al., 2002; Dooley, Lowenstein, Jenton, Fitgerald, \& Brubaker, 2008; Hannestad, Rortveit, Sandvik, \& Hunskaar, 2000).

Cognitive decline is also prevalent in older adults. In a sample of 660 nondemented participants between the ages of 65 and 75 years, 18\% had deficits in multiple cognitive domains (Manly et al., 2005). In fact, UI research on nursing home residents consistently supports an association between UI and cognitive decline (Hunskaar, Ostbye, \& Borrie, 1998; Palmer, Baumgarten, Langenberg, \& Carson, 2002; Wetle et al., 1995). For instance, in a study using multivariate analysis, patients lacking spatial and temporal orientation had a 3.6 times greater risk of being incontinent than those with a normal orientation (Aggazzotti et al., 2000). However, among nursing home residents, this correlation may also reflect a state of frailty that manifests in a myriad of symptoms without clear and distinct causal linkages.

Indeed, in relatively more healthy community-dwelling women, the association between UI and cognition remains ambiguous, with some studies supporting a relationship while others do not. A population-based cross-sectional study involving 1995 community-dwelling women did not show any relationship between an individual's score on the Mini-Mental State Examination (MMSE) and UI (Wetle et al., 1995). However, 
a more recent community-based study reported an association between cognitive impairment, defined as a score below 24 on the MMSE, and the prevalence of UI (Rait et al., 2005). Still, after adjusting for age, sex, residence, marital status, health, hearing, vision, medication, and falls, the association was of borderline statistical significance (odds ratio, $\mathrm{OR}=1.3,95 \%$ confidence interval, CI $[1.0,1.6]$ ). Another 6-year longitudinal study of 6349 community-dwelling women indicated that women with recent cognitive decline (i.e., 1 standard deviation, SD, beyond the mean decline and in the 6 years period preceding the incontinence assessment) were more likely to report that UI interfered with their daily activities (OR = 1.55, 95\% CI [1.10-2.17] for decline in MMSE score; OR $=1.53,95 \%$ CI [1.01-2.31] for decline in processing speed as assessed by the Digit Symbol Substitution Test; Huang, Brown, Thom, Fink, \& Yaffe, 2007). However, women with cognitive decline did not report any more UI symptoms or a higher frequency of UI than those without cognitive decline. Finally, a 10-year longitudinal study of over 5000 women aged 65 years and older found no significant association between moderate $(<78)$ or severe $(<50)$ cognitive impairment on the modified Mini-Mental Status (3MS) test and the incidence of UI (Ostbye et al., 2004). Contrary to studies on nursing home residents, studies on community-dwelling women, such as those discussed above, have identified no consistent findings regarding the relationship between cognitive decline and UI.

However, the divergent results among studies could be explained by the use of general, nonspecific indexes of cognitive functioning, such as the MMSE or 3MS. Such measures of general mental status do not permit the dissociation of cognitive functions that may ultimately play a critical role in the relationship between cognition and UI. In a recent study of 40 women ages 60 to 79 years, comparing 20 continent women to 20 with urgency UI, a trend emerged indicating that continent women performed better than those with UI on tasks recruiting working memory and executive functions (as per the Operation Span, OSPAN, task and the Wisconsin Sorting Card test; Morris, 2007 Morris, C. 2007. Differences in the function of the prefrontal cortex between women with urge urinary incontinence and continent cohorts. Neurology and Urodynamics, 26: 610-611. ).

Further, a non-gender-specific 2010 study using magnetic resonance imaging (MRI) found an association between white matter hyperintensities, moderate to severe UI (present in $38 \%$ of participants with no distinction between urgency, mixed, and stress UI), and reduced executive function (as measured by the Trail Making Test, Part B; the Stroop Color-Word test; and the California Computerized Assessment Package, sequential reaction time test; Wakefield et al., 2010). Unfortunately, gender-disaggregated data were not provided, and $40 \%$ of the 99 participants were men. Nevertheless, this suggests that UI may not be associated with general cognitive decline but, more specifically, to a decline in executive function: This is supported by the presence of increased white matter hyperintensities, a condition found in both UI and executive function decline. Knowing whether UI is more strongly associated with executive functioning could have implications for the modalities and format in which clinicians approach UI treatments. Moreover, it would support new approaches such as combined cognitive and pelvic-floor-muscle training, which could be more effective than pelvic-floor-muscle training alone.

Yet, if there is an association between cognition and UI, it may not be homogeneous among the different types of incontinence. Urgency UI has been associated with a lower score on both the MMSE (Griffiths et al., 1994) and the Cambridge Cognitive Examination (Griffiths, 1998). More recently, Morris (2007) observed a trend for poorer performance in community-dwelling women suffering from urgency UI $(n=20)$ than in continent women $(n=20)$. No similar comparisons have been made in women with either stress or mixed UI, nor between the three types of UI. This is important since stress and mixed UI are the two most prevalent types of UI in older women, hence, the most frequently encountered in rehabilitation interventions. This is also why the present study dissociated women with stress and mixed UI. 
In this study, women with stress and mixed UI, as well as continent women, were recruited to complete a battery of cognitive tests. It was hypothesized that women with either stress or mixed UI would show greater deficits on executive control tests than would continent women.

\section{METHOD}

The study was approved by the institutional review boards of the Institut universitaire de gériatrie de Montréal, the Jewish General Hospital, the Maisonneuve Rosemont Hospital, and the Centre Hospitalier Universitaire de Montréal.

Participants

One hundred and fifty-five women aged 60 years and older participated in the present study. They were recruited through advertisements placed in local newspapers and public places. Participants received a $\$ 50$ (Canadian) compensation for transportation. Inclusion criteria were: (a) 60 years old or older, (b) ambulatory, (c) continent or describing a pattern of stress or mixed UI as defined by the Urogenital Distress Inventory (UDI), and (d) having experienced, for those with stress or mixed UI, urinary leakage at least once a week during the previous three months (Shumaker, Wyman, Uebersax, McClish, \& Fantl, 1994). Participants were excluded if they had urgency UI or a score of 26 or less on the MMSE, terminal cancer, severe arthritis, a stroke, neurological or demyelization diseases, myopathies, indwelling urinary catheters, or any illness likely to influence cognitive function measurements. The latter criteria were chosen to eliminate frail participants, who have a higher risk of showing cognitive decline. Further, cognitive screening specifically excluded women with cognitive impairment such as dementia, in case UI is in fact part of the dementia syndrome.

Sociodemographic data were collected: age, level of education, body mass index (BMI), subjective general health status via the (short form) SF-12 Health Survey (Gandek et al., 1998), and lower-limb strength via the Sit-to-Stand Test.

Urinary incontinence assessment

The Urogenital Distress Inventory (UDI) was used to evaluate continence status and to differentiate among UI types in selecting participants. This test is specifically designed to assess symptoms associated with incontinence in women and is less invasive than other UI assessments. It contains 19 questions on lower urinary-tract symptoms and has been shown to have a good level of validity, reliability, and responsiveness among community-dwelling women and women over 60 . Continence, as a diagnostic status based on the UDI, was defined as no reported urinary leakage. Stress UI status was defined by reported leakage episodes on effort, exertion, sneezing, or coughing. Urgency UI status was defined by a reported leakage episode related to urgency (a sudden, intense desire to urinate), and the women were excluded from the study. Finally, mixed UI status was defined by the reported presence of both stress and urgency UI symptoms. Although the questionnaire is self-reported, trained female evaluators completed the UDI questionnaire with each of the participants to ensure the questions were well understood.

Cognitive assessments

The cognitive battery of tests consisted of eight tasks.

1.Mini-Mental State Examination (Folstein, \& McHugh, 1975). This is a brief 30-point questionnaire test that is used to screen for cognitive impairment. 
2.Similarities, Wechsler Adult Intelligence Scale-Third Edition (Wechsler, 1997). This task measures verbal abstract reasoning. Participants explain how two words are alike (e.g., orange and banana). Similarities subtest is considered to be a strong measure of crystallized intelligence.

3.Digit Span Forward, WAIS-III (Wechsler, 1997). This test measures short-term memory. The examiner reads a string of random digits out loud, at a rate of one per second (one series), after which the participant must repeat each digit in the same order. The string of digits in each series increases gradually (i.e., adding one or two digits at a time, from a string of 2 digits to upwards of 10). The dependent variable score is based on the number of correctly repeated series.

4.Digit Span Backward, WAIS-III (Wechsler, 1997). This WAIS-III subtask, a measure of working memory, is similar to the Digit Span Forward test, but the participant is instructed to repeat the string of digits in reverse order. The dependent variable score is based on the longest recalled series.

5.Digit Symbol Substitution, WAIS-III (Wechsler, 1997). This test assesses psychomotor speed (Lezak, Howieson, \& Loring, 2004). Participants use a response key to associate symbols to numbers (1 to 9). The dependent variable is the number of items completed in $120 \mathrm{~s}$.

6.Modified Stroop Test (Chatelois et al., 1996). This test includes four conditions; time to complete each task is the dependent variable. The two baseline conditions involve reading color-words (red, green, etc.) printed in black ink (word reading) and naming colored patches (color naming). These conditions rely predominantly on speed of processing and simple attention. In the third condition, participants name the color-word whose typeface color is incongruent (dissonant) with its name (e.g., the word blue printed in red font). This third condition assessed inhibition. Finally, in the fourth condition, participants switch back and forth between naming the dissonant ink colors and reading the words. This fourth condition is known to be strongly associated with flexibility - that is, the ability to switch one's focus of attention from one task to another.

7.Trail Making Test, Parts A and B (Tombaugh, 2004). Visual search, scanning, and speed of processing is assessed using the Trail Making Test Part A. Participants use a pencil to link up numbers (from 1 to 25) in a continuous line as fast as possible. The Trail Making Test Part B assesses flexibility of attention (also called switching). In this part, the participant alternates between letters in alphabetical order and numbers in ascending order (1-A-2-B-3-C, etc.). In both, the time required to complete the task is used as the dependent variable.

8.Computerized dual-task (similar to the one used by Bherer et al., 2005 and Erickson et al., 2007). This includes two visual identification tasks, performed both separately and concurrently. In the first block, participants identify the direction of an arrow (left or right) by pressing "K" (for left) or "L" (for right) on a keyboard with their right hand. In the second block, participants identify the color of a square by pressing "A" (for red) or "S" (for green) with their left hand. Trials from these two blocks (single-pure trials) are an indicator of general speed. In the next block, the arrows and the colored squares were presented, in a random pattern, either alone (single-mixed trials) or simultaneously (dual-mixed trials). Performance in the single-mixed trials reflects the ability to deal with multiple task-sets simultaneously and is considered to tap working memory. Performance in the dual-mixed trials reflects the ability to coordinate perception, processing, and response to two simultaneous tasks and indexes divided attention. Reaction times (RTs) are used as the dependent variables.

Executive processes are implicated in complex cognition, such as problem solving and task coordination, thereby modifying behavior as appropriate in light of changes inhibiting prepotent intermediate outcomes and as needed (Carpenter, Just, \& Reichle, 2000). In the present study's cognitive evaluations, the inhibition 
and flexibility conditions of the Modified Stroop Test, the Trail Making Test Part B, and the single- and dual-mixed trials of the computerized dual-task were all considered as measures of executive processes.

Statistical approach

As several cognitive measures were collected, multivariate analyses of variance (MANOVAs) were used to assess differences between the continent and stress and mixed UI groups. When significant differences were observed ( $\mathrm{p}$ <05), pairwise comparisons were performed using Bonferroni post hoc tests. All of the analyses were conducted using SPSS for Windows (Rel. 11.0.1. 2001; Chicago: SPSS Inc.).

\section{RESULTS}

An initial MANOVA was performed in order to verify whether the three groups (continent women, stress UI women, and mixed UI women) were comparable on age, level of education, body mass index (BMI), subjective general health (SF-12), lower limb strength (sit to stand test), general cognitive state (MMSE), and crystallized intelligence (Similarities subtest). Table 1 presents each group's mean and standard deviation for each measure. MANOVA results indicated that none of the variables differed significantly among the groups, Wilks's lambda $=.89, \mathrm{~F}(14,292)=1.27, \mathrm{p}=.223, \mathrm{n}=.057$.

TABLE 1 Characteristics of women in the urinary incontinence groups-MANOVA

\begin{tabular}{|c|c|c|c|c|c|c|c|c|c|}
\hline \multirow[b]{2}{*}{ Characteristic } & \multicolumn{2}{|c|}{$\begin{array}{l}\text { No } \\
\text { (continent) } \\
\text { 35) }\end{array}$} & \multicolumn{2}{|c|}{$\begin{array}{l}\text { Stress UI (n } \\
=43)\end{array}$} & \multicolumn{2}{|c|}{$\begin{array}{l}\text { Mixed UI (n } \\
=78)\end{array}$} & \multicolumn{3}{|c|}{$\begin{array}{l}\text { Tests of between- } \\
\text { subject effects }\end{array}$} \\
\hline & Mean & SD & Mean & SD & Mean & SD & $\begin{array}{l}F(2, \\
156)\end{array}$ & p & $\mathbf{n}$ \\
\hline Age (years) & 66.54 & 5.82 & 68.37 & 5.88 & 68.14 & 6.31 & 1.05 & .35 & .01 \\
\hline Level of education ${ }^{\text {a }}$ & 3.43 & 0.78 & 3.19 & 0.98 & 3.10 & 0.95 & 1.29 & .22 & .02 \\
\hline $\begin{array}{l}\text { Body } \\
\text { (score) }\end{array}$ & 24.35 & 4.31 & 25.38 & 4.23 & 25.21 & 3.62 & 0.768 & .47 & .01 \\
\hline $\begin{array}{l}\text { SF-12 health survey } \\
\text { (score) }\end{array}$ & 54.51 & 6.06 & 51.84 & 7.48 & 52.77 & 6.64 & 1.55 & .22 & .02 \\
\hline Sit-to-stand test & 13.03 & 3.61 & 13.33 & 3.58 & 12.47 & 3.39 & 0.89 & .41 & .01 \\
\hline $\begin{array}{l}\text { Mini-Mental State } \\
\text { Examination (score) }\end{array}$ & 29.09 & 1.04 & 29.05 & 1.02 & 28.81 & 0.99 & 1.29 & .285 & 0.2 \\
\hline Similarity (score) & 24.09 & 5.29 & 21.29 & 6.21 & 21.71 & 5.69 & 2.68 & .72 & .03 \\
\hline \multicolumn{10}{|c|}{ Note. MANOVA = multivariate analysis of variance; $\mathrm{UI}=$ urinary incontinence. } \\
\hline
\end{tabular}


Two other MANOVAs were performed to compare the groups on neuropsychological tests. One MANOVA included measures that load on attention and speed of processing (Digit Symbol Substitution, Digit Span Forward, Digit Span Backward, Modified Stroop reading and naming conditions, Trail Making Test Part A, and RTs on single-pure trials), and the other MANOVA included measures that load heavily on executive functioning (Modified Stroop inhibition and flexibility conditions, Trail Making Test Part B, $\mathrm{RT}$ in the single and dual-mixed trials). Results indicated that attention and speed of processing do not significantly differed among the groups, Wilks's lambda $=.89, \mathrm{~F}(14,292)=1.64, \mathrm{p}=.066, \mathrm{n}=.073$, while executive functioning does, Wilks's lambda $=.88, \mathrm{~F}(10,292)=1.93, \mathrm{p}<.05, \mathrm{n}=.061$. Moreover, no between-subject effects were significant on the measures of attention and speed of processing (see Table 2). By contrast, every measure of executive functioning showed significant between-subject effects (see Table $3)$.

TABLE 2 Attention/processing speed performance of women in urinary incontinence groupsMANOVA

\begin{tabular}{|c|c|c|c|c|c|c|c|c|c|}
\hline \multirow[b]{2}{*}{ Performance } & \multicolumn{2}{|c|}{$\begin{array}{lr}\text { No } & \text { UI } \\
(\text { continent }) & (\mathrm{n}= \\
35) & \end{array}$} & \multicolumn{2}{|c|}{$\begin{array}{l}\text { Stress UI }(n= \\
\text { 43) }\end{array}$} & \multicolumn{2}{|c|}{$\begin{array}{l}\text { Mixed UI }(\mathrm{n}= \\
\text { 78) }\end{array}$} & \multicolumn{3}{|c|}{$\begin{array}{l}\text { Tests of between- } \\
\text { subject effects }\end{array}$} \\
\hline & Mean & SD & Mean & SD & Mean & SD & $\begin{array}{l}\mathrm{F}(2, \\
156)\end{array}$ & $\mathbf{p}$ & $\mathbf{n}$ \\
\hline $\begin{array}{l}\text { Digit forward } \\
\text { (score) }\end{array}$ & 9.49 & 2.06 & 9.05 & 1.85 & 9.68 & 2.42 & 1.33 & .27 & .02 \\
\hline $\begin{array}{l}\text { Digit } \\
\text { substitution } \\
\text { (score) }\end{array}$ & 66.80 & 11.70 & 61.79 & 12.12 & 62.60 & 16.83 & 1.15 & .31 & .02 \\
\hline $\begin{array}{l}\text { Digit backward } \\
\text { (score) }\end{array}$ & 6.60 & 1.70 & 5.91 & 2.16 & 6.47 & 2.46 & 1.19 & .31 & .02 \\
\hline $\begin{array}{l}\text { Stroop-word } \\
\text { reading(s) }\end{array}$ & 41.72 & 6.03 & 44.34 & 6.63 & 43.23 & 7.42 & 1.38 & .25 & .02 \\
\hline $\begin{array}{l}\text { Stroop-color } \\
\text { naming(s) }\end{array}$ & 64.18 & 12.20 & 62.80 & 9.93 & 66.77 & 13.72 & 1.52 & .22 & .02 \\
\hline $\begin{array}{l}\text { Trail Making } \\
\text { Test A (s) }\end{array}$ & 38.70 & 10.53 & 37.55 & 9.14 & 40.97 & 14.09 & 1.20 & .30 & .02 \\
\hline $\begin{array}{l}\text { Single-pure } \\
\text { trials (ms) }\end{array}$ & 706.81 & 120.34 & 722.52 & 162.77 & 761.27 & 188.56 & 1.53 & .22 & .02 \\
\hline
\end{tabular}

Note. MANOVA = multivariate analysis of variance; $\mathrm{UI}=$ urinary incontinence. 
TABLE 3 Executive functioning performance of women in urinary incontinence groups-MANOVA

\begin{tabular}{|c|c|c|c|c|c|c|c|c|c|}
\hline \multirow[b]{2}{*}{ Performance } & \multicolumn{2}{|c|}{$\begin{array}{l}\text { No UI (continent) } \\
(\mathbf{n}=35)\end{array}$} & \multicolumn{2}{|c|}{ Stress UI $(n=43)$} & \multicolumn{2}{|c|}{$\begin{array}{l}\text { Mixed UI }(n= \\
78)\end{array}$} & \multicolumn{3}{|c|}{$\begin{array}{l}\text { Tests of between- } \\
\text { subject effects }\end{array}$} \\
\hline & Mean & SD & Mean & SD & Mean & SD & $\begin{array}{l}F(2, \\
156)\end{array}$ & $\mathbf{p}$ & $\mathbf{n}$ \\
\hline $\begin{array}{l}\text { Stroop- } \\
\text { inhibition (s) }\end{array}$ & 115.21 & 26.7 & 118.98 & 24.16 & 129.50 & 36.25 & 3.10 & .05 & .04 \\
\hline $\begin{array}{l}\text { Stroop- } \\
\text { switching (s) }\end{array}$ & 125.04 & 22.14 & 134.71 & 24.77 & 145.24 & 35.80 & 5.65 & .01 & .07 \\
\hline $\begin{array}{l}\text { Trail Making } \\
\text { Test B (s) }\end{array}$ & 80.88 & 24.55 & 87.40 & 29.29 & 97.24 & 38.00 & 3.27 & .04 & .04 \\
\hline $\begin{array}{l}\text { Single-mixed } \\
\text { trials (ms) }\end{array}$ & 1138.14 & 180.07 & 1116.17 & 255.17 & 1248.67 & 303.31 & 4.17 & .02 & .05 \\
\hline $\begin{array}{l}\text { Dual-mixed } \\
\text { trials (ms) }\end{array}$ & 1741.00 & 301.17 & 1691.91 & 383.13 & 1947.31 & 486.39 & 6.05 & .01 & .07 \\
\hline
\end{tabular}

Note. MANOVA = multivariate analysis of variance; UI = urinary incontinence.

In order to identify group differences, pairwise comparisons were performed for each executive functioning measure. Regarding the inhibition condition of the Modified Stroop Test, no comparison reached significance level. Conversely, women with mixed UI took significantly more time to complete the switching condition of the Modified Stroop Test than did continent women, $p \leq .01$. Similarly, women with mixed UI also took more time to complete the Trail Making Test Part B than did continent women, $\mathrm{p} \leq .05$.

In the computerized dual-task performances, women with mixed UI had significantly longer mean RT than women with stress UI in the single-mixed trials, $\mathrm{p} \leq .05$. However, RT differences between continent women and either UI group (stress or mixed) failed to reach significance. Finally, women with mixed UI had significantly longer mean RT than both continent women and women with stress UI, ps $\leq .05$. Note that no difference was observed on accuracy, $\mathrm{ps} \leq .05$, in the dual-task test and that the mean percentage of correct answers was above $95 \%$ for each group for all conditions. Continent women serve as a normative group to illustrate the distribution of performances in women with UI on measures of executive control (Figure 1). Overall, larger amount of women with UI are in the lower quartiles (third and fourth) of the normative group than in the upper quartiles. 

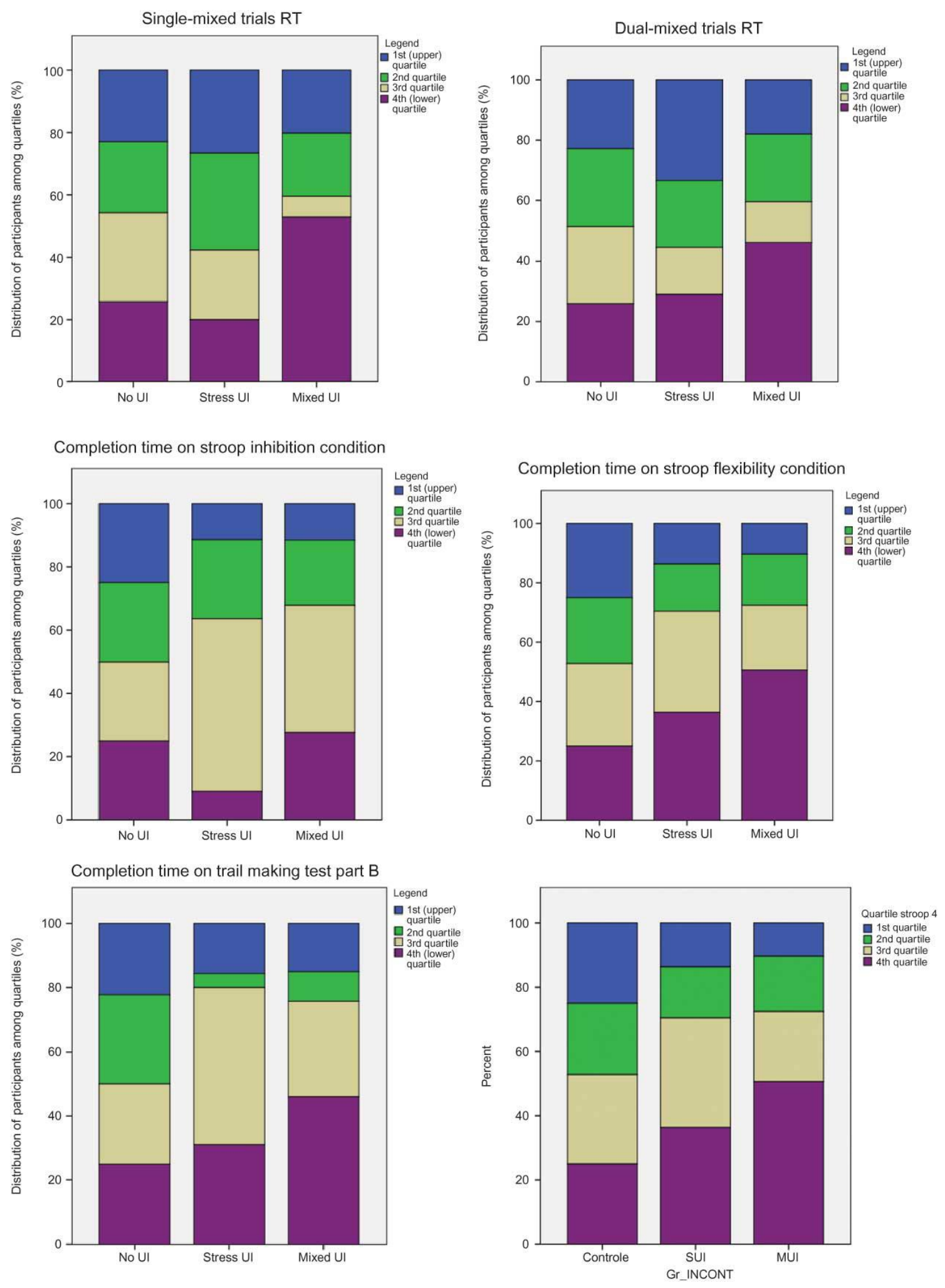

Figure 1. Performances in neuropsychological tests that discriminated women with no urinary incontinence to those with stress or mixed urinary incontinence. $\mathrm{RT}=$ reaction time; $\mathrm{SUI}=$ stress urinary incontinence; $\mathrm{MUI}=$ mixed urinary incontinence. To view a color version of this figure, please see the online issue of the Journal. 
Clinical relevance of results

In the switching condition of the Modified Stroop Test, women with mixed UI were the only group to attain the "low average" range of performance (23th percentile) while the continent and stress UI groups remained within the "normal average" range, the 50th and 36th percentile, respectively (Chatelois et al., 1996).

Similarly, in the flexibility condition of the Trail Making Test Part B, women with mixed UI were the only group in the "low average" range. The mean performance of the mixed UI group fell within the 20th and 30th percentiles, the stress UI group within the 30th and 40th percentiles, and the continent group within the 40th and 50th percentiles, in accordance with normative data for 65-69-year-old adults (Tombaugh, 2004).

\section{DISCUSSION}

This study assessed the relationship between cognitive functions and the presence of mixed and stress UI in older women. Both UI groups and the control group were carefully selected from healthy communitydwelling populations and were comparable in age, education, health status, lower-limb strength, general cognitive state, and crystalized intelligence. On attention and processing speed measures, women with UI were no different than continent women. Conversely, compared to continent women, women with mixed UI had significantly lower performances on several measures of executive control. Indeed, women with mixed UI took more time than continent women to complete the switching condition of the Modified Stroop Test and the flexibility condition of the Trail Making Test (Part B). Women with mixed UI also had the poorest performances when compared to the two other groups on the computerized dual-task, which requires a person to maintain multiple task-sets (working memory) and to share attention between two concurrent tasks (divided attention).

Our results are consistent with previous studies reporting no differences between community-dwelling women with and without UI on the Mini-Mental State Examination, a gross measure of general mental state (Ostbye et al., 2004; Wetle et al., 1995). However, the results from the present study are novel, showing that executive control deficits are strongly associated with mixed UI. Moreover and specifically, they indicate that working memory, as required to maintain multiple stimulus-response alternatives, switching ability, and divided attention may play a critical role in incontinence in older women. It is worth noting that the results from many of the executive control tasks showed a consistent pattern of specific deficits in the executive control condition, while nonexecutive conditions did not show appreciable differences among the groups.

Another important finding of the present study is that even among cognitively functional women, who showed comparable performance on the MMSE, a more specific cognitive assessment involving executive control tasks was able to characterize between continent women and those suffering from UI. This suggests that a more comprehensive neuropsychological assessment could help characterize incontinence and, perhaps, identify appropriate interventions.

Although the results reported here suggest a relationship between mixed UI and executive control deficits, it remains unclear whether there is a causal relation between these two variables and the direction of this causality. Moreover, one could argue that women with mixed UI did not perform as well on the cognitive tests because they were more prone to worrying about potential urine loss, a distraction that could have disrupted executive functioning. A recent review of functional brain imaging suggests that an exaggerated cortical response in urgency UI participants is observed secondary to both an increase in bladder volume and a strong (urgency) sensation to void (Griffiths \& Tadic, 2008). This supports the hypothesis that 
cognitive function is potentially affected by an attempt to maintain control of the pelvic floor muscle and bladder. However, to minimize the impact of such a distraction, the women in this study were asked to empty their bladder prior to beginning the cognitive assessments.

It could be argued that the association between UI and executive function is, in fact, caused by a shared variable: a low global health condition, also called frailty. Indeed, frailty, a clinical syndrome, is associated with early cognitive decline, incident falls, worsening mobility or activities of daily living disability, hospitalizations, and death (Fried et al., 2001). However, this explanation is unlikely since each group showed equivalent subjective health conditions and lower-limb strength, suggesting equivalent general health conditions among the groups.

Additionally, it could be argue that that mixed UI and low executive control are related through a common etiology, such as white matter hyperintensities. No study has yet to compared the amount of white matter hyperintensities associated with the different types of UI; therefore, common neural causes of UI and executive control deficits remain speculative. Contrary to women with mixed UI, no differences were observed between women with stress UI and continent women on measures of executive control. In other studies, executive control deficits were, however, observed in women with urgency UI (Morris, 2007); thus, it is possible that the cognitive function involved in intentional control, implicated in urgency UI, also plays an important role in the relation between executive control deficits and this UI type. Since the present study did not include women with urgency UI, a definitive conclusion awaits further studies.

Finally, mixed UI tends to be more bothersome and results in more severe symptoms than either stress or urgency UI, which could also account for the differences (Bump, Norton, Zinner, \& Yalcin, 2003; Dooley et al., 2008). Consequently, one could argue that executive-control deficits were observed only in the mixed UI group because it is a more severe type of incontinence: The severity of UI could account for the difference found in the study. This could also explain why, on the executive control measures, women with stress UI fell between continent women and those with mixed UI in terms of performance outcomes.

It is important to mention that the present study is observational; thus, no causal relationship between UI and cognition could be confirmed. Moreover, the presence and types of UI were measured using the Urogenital Distress Inventory (UDI), chosen because of its noninvasiveness and because it has demonstrated good psychometric properties. Therefore, no direct diagnosis, secondary to the UDI, was used to categorize the participants into UI groups.

Overall, the present study has important clinical implications. First, it suggests that clinicians should take into account executive-control deficits in clinical interventions for women with mixed UI. Second, combining cognitive training and pelvic-floor-muscle training may be more effective than pelvic-floormuscle training alone. Cognitive training improves performance on tasks that differ from the trained task (transfer tasks; Lussier, Gagnon, \& Bherer, 2012), and it also shows interesting impacts on activities of daily living. For instance, Cassavaugh and Kramer (2009) demonstrated that cognitive training could lead to enhanced automotive driving abilities. More recently, Li et al. (2010) showed that improving attentional control with a divided-attention training program leads to enhanced motor control in balance tests. Nonetheless, further experimental studies are required in order to increase our understanding of the actual relationship between executive-control deficits and UI. For instance, if cognitive training, such as dual-task training, leads to a reduction in UI severity, it would suggest that UI severity is, at least partially, dependent on executive control. Conversely, if pelvic-floor-muscle training leads to an improvement in women's executive control, one could conclude that UI severity is somehow disrupting and altering executive control. This important knowledge could influence future clinical approaches to UI and, more specifically, mixed UI in older women. 
Notes

This research was supported by grants from the Canadian Institute of Health Research (CIHR) and the Fond de la Recherche en Santé du Québec (FRSQ), by CIHR and FRSQ salary support to L.B. and C.D., and a Natural Sciences and Engineering Research Council of Canada (NSERC) fellowship to M.L. The authors wish to thank Muriel Jadin, project coordinator, as well as the participants for their commitment in this study. The authors declare no conflict of interest.

\section{REFERENCES}

Abrams, P., Cardozo, L., Fall, M., Griffiths, D., Rosier, P., Ulmsten, U., ... and Wein, A. 2002. The standardisation of terminology of lower urinary tract function: Report from the Standardisation SubCommittee of the International Continence Society. Neurourology and Urodynamics, 21: 167-178.

Aggazzotti, G., Pesce, F., Grassi, D., Fantuzzi, G., Righi, E., De Vita, D., ... and Artibani, W. 2000. Prevalence of urinary incontinence among institutionalized patients: A cross-sectional epidemiologic study in a midsized city in northern Italy. Urology, 56: 245-249. [CrossRef], [PubMed], [Web of Science ®] OpenURL Universite de Montreal

Bherer, L., Kramer, A. F., Peterson, M. S., Colcombe, S., Erickson, K. and Becic, E. 2005. Training effects on dual-task performance: Are there age-related differences in plasticity of attentional control?. Psychology and Aging, 20: 695-709.

Bump, R. C., Norton, P. A., Zinner, N. R. and Yalcin, I. 2003. Mixed urinary incontinence symptoms: Urodynamic findings, incontinence severity, and treatment response. Obstetrics \& Gynecology, 102: 7683.

Carpenter, P. A., Just, M. A. and Reichle, E. D. 2000. Working memory and executive function: Evidence from neuroimaging. Current Opinion in Neurobiology, 10: 195-199.

Cassavaugh, N. D. and Kramer, A. F. 2009. Transfer of computer-based training to simulated driving in older adults. Applied Ergonomics, 40: 943-952.

Chatelois, J., Van Der Linden, M., Rouleau, N., De Courcy, R., Crépeau, F. and Malenfant, A. 1996.

Stroop Flexibilité-4 color Unpublished manuscriptOpenURL Universite de Montreal

Dooley, Y., Lowenstein, L., Jenton, K., Fitgerald, M. and Brubaker, L. 2008. Mixed incontinence is more bothersome than pure incontinence subtypes. International Urogynecology Journal and Pelvic Floor Dysfunction, 19: 1359-1362.

Erickson, K. I., Colcombe, S. J., Wadhwa, R., Bherer, L., Peterson, M. S., Scalf, P. E., ... and Kramer, A. F. 2007. Training-induced functional activation changes in dual-task processing: An fMRI study. Cerebral Cortex, 17: 192-204.

Folstein, M. F., Folstein, S. E. and McHugh, P. R. 1975. "Mini-mental state.” A practical method for grading the cognitive state of patients for the clinician. Journal of Psychiatric Research, 12: 189-198.

Fried, L. P., Tangen, C. M., Walston, J., Newman, A. B., Hirsch, C., Gottdiener, J., ... and McBurnie, M. A. 2001. Frailty in older adults: Evidence for a phenotype. The Journals of Gerontology: Series A, Biological Sciences and Medical Sciences, 56: M146-M156. 
Gandek, B., Ware, J. E., Aaronson, N. K., Apolone, G., Bjorner, J. B., Brazier, J. E., ... and Sullivan, M. 1998. Cross-validation of item selection and scoring for the SF-12 Health Survey in nine countries: Results from the IQOLA Project: International Quality of Life Assessment. Journal of Clinical Epidemiology, 51: $1171-1178$.

Griffiths, D. 1998. Clinical studies of cerebral and urinary tract function in elderly people with urinary incontinence. Behavioral Brain Research, 92: 151-155.

Griffiths, D. and Tadic, S. D. 2008. Bladder control, urgency, and urge incontinence: Evidence from functional brain imaging. Neurourology and Urodynamics, 27: 466-474.

Griffiths, D. J., McCracken, P. N., Harrison, G. M., Gormley, E. A., Moore, K., Hooper, R., ... and Triscott, J. 1994. Cerebral aetiology of urinary urge incontinence in elderly people. Age and Ageing, 23: 246-250.

Hannestad, Y. S., Rortveit, G., Sandvik, H. and Hunskaar, S. 2000. A community-based epidemiological survey of female urinary incontinence: The Norwegian EPINCONT study: Epidemiology of Incontinence in the County of Nord-Trondelag. Journal of Clinical Epidemiology, 53: 1150-1157.

Huang, A. J., Brown, J. S., Thom, D. H., Fink, H. A. and Yaffe, K. 2007. Urinary incontinence in older community-dwelling women: The role of cognitive and physical function decline. Obstetrics \& Gynecology, 109: 909-916.

Hunskaar, S., Ostbye, T. and Borrie, M. J. 1998. Prevalence of urinary incontinence in elderly Canadians with special emphasis on the association with dementia, ambulatory function, and institutionalization. Norwegian Journal of Epidemiology, 8: 177

Lezak, M. D., Howieson, D. B. and Loring, D. W. 2004. Neuropsychological assessment, 4th, New York, NY: Oxford University Press.

Li, K. Z. H., Roudaia, E., Lussier, M., Bherer, L., Leroux, A. and McKinley, P. A. 2010. Benefits of cognitive dual-task training on balance and mobility in healthy older adults. The Journals of Gerontology: Series A, Biological Sciences and Medical Sciences, 65: 1344-1352.

Lussier, M., Gagnon, C. and Bherer, L. 2012. An investigation of response and stimulus modality transfer effects after dual-task training in younger and older. Frontiers in Human Neuroscience, 6: 129

Manly, J. J., Bell-McGinty, S., Tang, M. X., Schupf, N., Stern, Y. and Mayeux, R. 2005. Implementing diagnostic criteria and estimating frequency of mild cognitive impairment in an urban community.

Archives of Neurology, 62: 1739-1746.

Milson, I., Altman, D., Lapitan, M. C., Nelson, R., Sillen, U. and Thom, D. 2009. "Epidemiology of urinary (UI) and faecal (FI) incontinence and pelvic organ prolapse (POP)". In Fourth international consultation on incontinence, Edited by: Abrams, P., Cardozo, L., Khoury, S. and Wein, A. 37-111. France: Health Public Publication.

Morris, C. 2007. Differences in the function of the prefrontal cortex between women with urge urinary incontinence and continent cohorts. Neurology and Urodynamics, 26: 610-611.

Ostbye, T., Seim, A., Krause, K. M., Feightner, J., Hachinski, V., Sykes, E. and Hunskaar, S. 2004. A 10year follow-up of urinary and fecal incontinence among the oldest old in the community: The Canadian Study of Health and Aging. Canadian Journal on Aging, 23: 319-331. 
Palmer, M. H., Baumgarten, M., Langenberg, P. and Carson, J. L. 2002. Risk factors for hospital-acquired incontinence in elderly female hip fracture patients. Journals of Gerontology Series A: Biological Sciences and Medical Sciences, 57(, M672-M677)

Rait, G., Fletcher, A., Smeeth, L., Brayne, C., Stirling, S., Nunes, M., ... and Tulloch, A. J. 2005.

Prevalence of cognitive impairment: Results from the MRC trial of assessment and management of older people in the community. Age and Ageing, 34: 242-248.

Shumaker, S. A., Wyman, J. F., Uebersax, J. S., McClish, D. and Fantl, J. A. 1994. Health-related quality of life measures for women with urinary incontinence: The incontinence impact questionnaire and the urogenital distress inventory. Continence Program in Women (CPW) Research Group. Quality of Life Research, 3: 291-306.

Tannenbaum, C., Mayo, N. and Ducharme, F. 2005. Older women's health priorities and perceptions of care delivery: Results of the WOW health survey. Canadian Medical Association Journal, 173: 153-159.

Tombaugh, T. N. 2004. Trail Making Test A and B: Normative data stratified by age and education. Archives of Clinical Neuropsychology, 19: 203-214.

Wakefield, D. B., Moscufo, N., Guttmann, C. R., Kuchel, G. A., Kaplan, R. F., Pearlson, G. and Wolfson, L. 2010. White matter hyperintensities predict functional decline in voiding, mobility, and cognition in older adults. Journal of the Americam Geriatrics Society, 58: 275-281.

Wechsler, D. 1997. Wechsler adult intelligence scale, 3rd, San Antonio, TX: The Psychological Corporation. OpenURL Universite de Montreal

Wetle, T., Scherr, P., Branch, L. G., Resnick, N. M., Harris, T., Evans, D. and Taylor, J. O. 1995. Difficulty with holding urine among older persons in a geographically defined community: Prevalence and correlates. Journal of the American Geriatrics Society, 43: 349-355.

This is the accepted version of the following article: Lussier M, Renaud M, Chiva-Razavi S, Bherer L, Dumoulin C. (2013) Are stress and mixed urinary incontinence associated with impaired executive control in community-dwelling older women? Journal of Clinical and Experimental Neuropsychology; 35(5):445454., which has been published in final form at http://www.tandfonline.com/doi/pdf/10.1080/13803395.2013.789483?needAccess=true 